\title{
Importance of Differential Diagnosis of a Possible Brain Tumor in Patients with Cervical Radiculopathy
}

\author{
Jin-Shup So, Young-Jin Kim, Sang-Koo Lee, Chun-Sung Cho \\ Department of Neurosurgery, Dankook University Hospital, Cheonan, Korea
}

Lesions occurring simultaneously in the somatosensory or motor cortex of the brain and the cervical spine are rare. Brain tumors can cause similar symptoms to cervical lesions which can lead to confusion in treatment priorities. Moreover, if cervical disease is noticeably observed in radiologic findings of a patient complaining of cervical radiculopathy with non-specific electromyography results, it is common to no longer perform further evaluation. Here we introduce two cases where the cause of cervical radiculopathy was first considered to be the result of a degenerative cervical disease but was later discovered to be a result of a brain tumor.

Key Words : Radiculopathy · Paresthesia · Brain neoplasms.

\section{INTRODUCTION}

Determining the diagnosis and cause of cervical radiculopathy is often difficult and confusing. A variety of disorders with similar symptoms have to be contemplated in the differential diagnosis including brachial plexopathy, entrapment syndrome, thoracic outlet syndrome, primary shoulder disease and intraspinal or extraspinal tumors ${ }^{1-4,7)}$. Intracranial brain tumors also, while very rare, should be considered as a cause of radiculopathy. It is extremely unlikely that the first presenting symptom of a brain tumor patient is only radiculopathy. If a patient had a past history of cervical spine surgery or was diagnosed with cervical degenerative disease, it is uncommon to request additional computerized tomography (CT) scans or magnetic resonance (MR) imaging of the brain.
We introduce two patients who were diagnosed with a brain tumor but initially presented with cervical radiculopathy and were considered to have an ordinary cervical disc disease. The aim of this report is to recommend that intracranial neoplasm be considered as a possibility of cervical radiculopathy.

\section{CASE REPORT}

\section{Case 1}

A 48-year-old man presented with intermittent headaches, radicular pain and paresthesia in both upper limbs, and mild motor weakness in his right upper limb. The pain (Visual analogue score [VAS], 7) was continuously radiating to his forearms, thumbs, index and middle fingers. Upon initial neuro-

- Received : May 24, 2021 •Revised : July 14, 2021 •Accepted : August 23, 2021

- Address for reprints : Young Jin Kim

Department of Neurosurgery, Dankook University Hospital, 201 Manghyang-ro, Dongnam-gu, Cheonan 05278, Korea

Tel : +82-41-550-6280, Fax : +82-41-550-6284, E-mail : spine1225@naver.com, ORCID : https://orcid.org/0000-0002-6770-3523

This is an Open Access article distributed under the terms of the Creative Commons Attribution Non-Commercial License (http://creativecommons.org/licenses/by-nc/4.0) which permits unrestricted non-commercial use, distribution, and reproduction in any medium, provided the original work is properly cited. 
logic exam, he had C6 dermatome paresthesia and paresis (manual muscle test, 4) with normal deep tendon reflexes (DTR; $2+$ ) of his entire right upper arm. A cervical spine CT scan showed prominent foraminal stenosis and uncovertebral joint hypertrophy in the C6-7 disc space (Fig. 1). Cervical MR imaging revealed a centro-lateral disc protrusion with a mild compressive effect on the dural sac at C5-6 disc level (Fig. 2A) as well as both right and left C6-7 foraminal stenosis (Fig. 2B). There was no electrophysiologic evidence of peripheral neuropathy and his symptoms did not improve on oral medication. Even though the symptoms, imaging and electrophysiologic test were slightly ambiguous, the authors concluded on C6-7 polyradiculopathy after consultation with a neurologist and radiologist. Also, the brain MR image taken 2 years prior to the hospital visit, displayed no abnormal lesions (Fig. 3). An anterior cervical discectomy and fusion with allograft bone at C6-7 was performed. Postoperative paresthesia and radiating pain in the left upper arm were relieved (VAS, 2) but motor
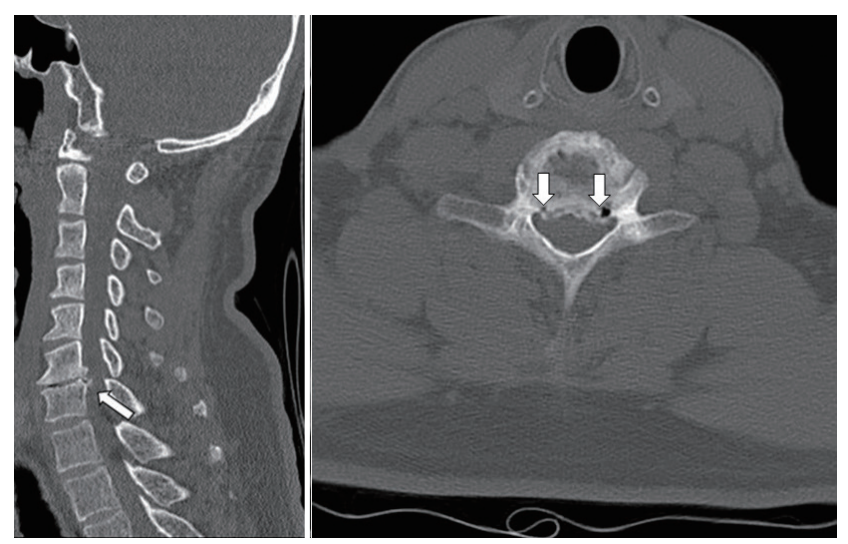

Fig. 1. Cervical computerized tomography scan showing prominent both foraminal stenosis (axial image white arrow) and uncovertebral joint hypertrophy (sagittal image white arrow). weakness of the right upper arm retrogressed gradually (manual muscle test, 4 to 3). Further evaluation of the brain was then performed via MR imaging and a well-defined intracranial brain tumor in the left fronto-parietal area was found (Fig. 4). Thus, he underwent a gross total tumor removal and the immune-histochemical stain and pathology report were consistent with meningioma. Three months after his discharge from the hospital, patient had a distinct improvement of his paresthesia, radiating pain of both arms and paresis on his right arm (manual muscle test, 3 to $4+$ ). Also, his head-
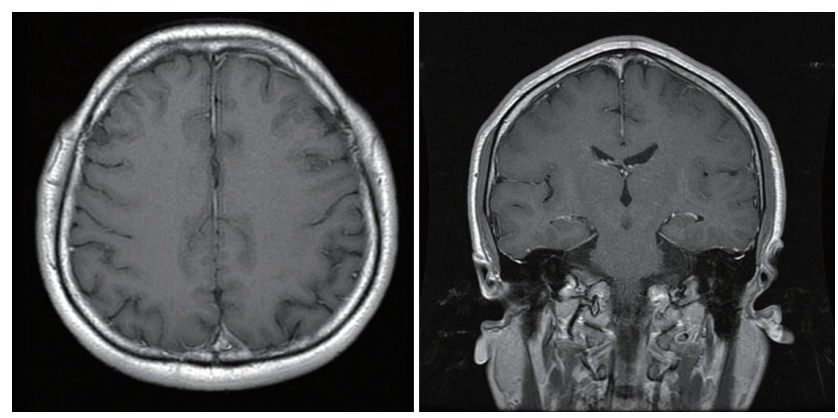

Fig. 3. Normal brain magnetic resonance imaging taken 2 years before the symptoms occurred.
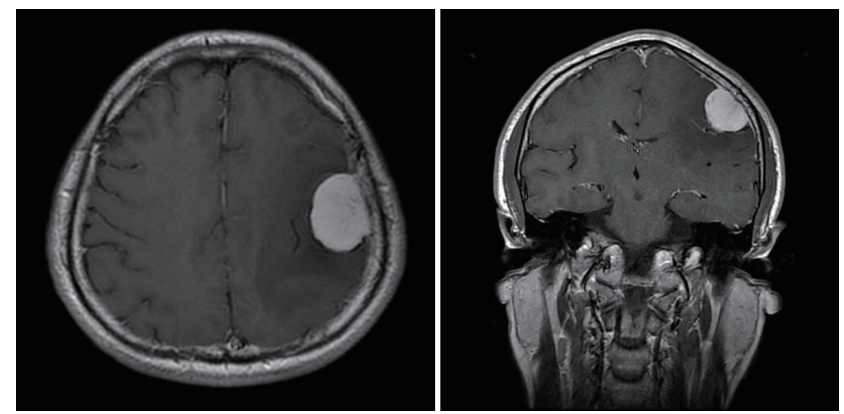

Fig. 4. New brain mass found on brain magnetic resonance imaging taken 1 week after cervical operation.
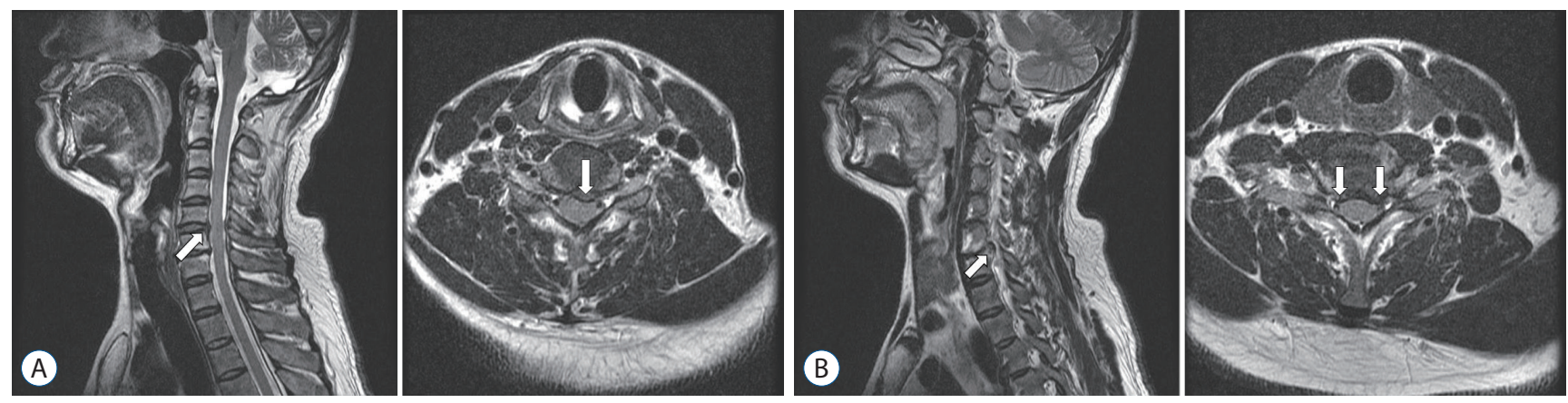

Fig. 2. A : Magnetic resonance imaging (MRI) revealing mild disc protrusion at the C5-6 disc level (white arrow). B : Preoperative MRI showing both foraminal stenosis at the C6-7 disc level (white arrow). 
aches were resolved.

\section{Case 2}

A 56-year-old man was admitted to our hospital who presented with radicular pain and paresis in his left upper limb and mild intermittent headaches. He had undergone an anterior cervical discectomy and fusion at a local spine hospital 15 months prior due to due to left upper radiculopathy and motor weakness caused by a cervical disc protrusion at C5-6 (Fig. 5).

Patient complained that his symptoms had mostly resolved after the surgery however, 10 days before admission, intermit-
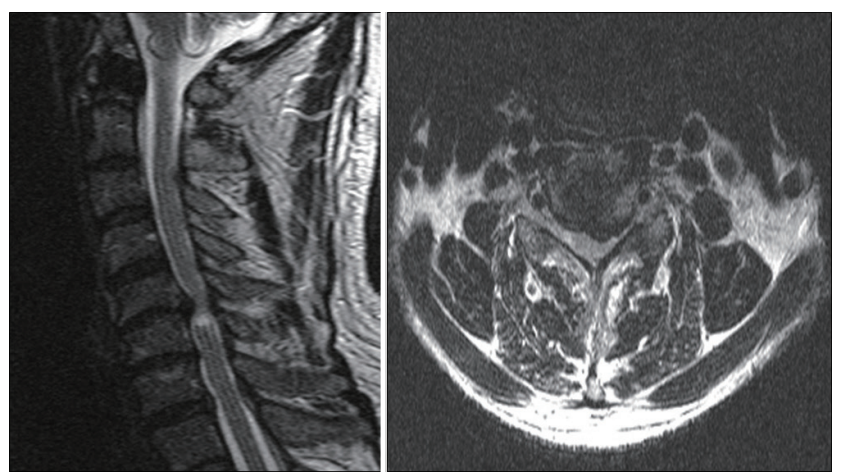

Fig. 5. Degenerative change and protrusion of cervical disc (C5-6 level) having a compressive effect on spinal cord.

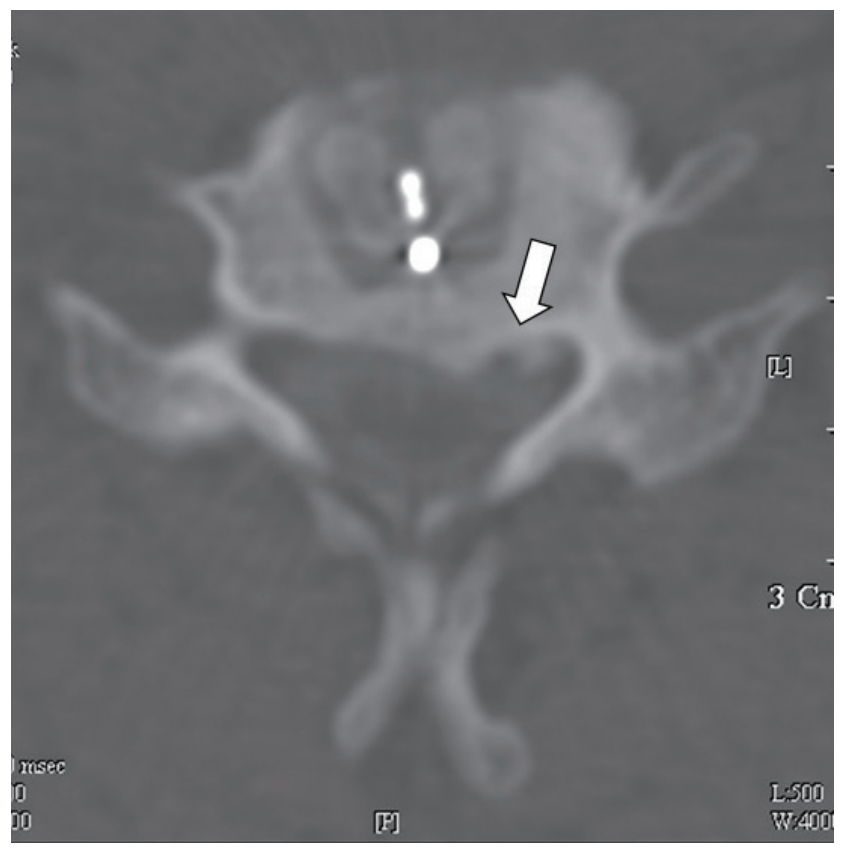

Fig. 6. Computerized tomography myelogram suggestive of left foraminal stenosis at C5-6 level due to bony spur (white arrow). tent headaches, radiating pain and sudden weakness of his left upper limb started.

Upon neurologic examination, the patient complained paresthesia, pain of his entire left arm and motor weakness (manual muscle test, 4), with normal DTR. A cervical spine X-ray showed a normal cervical alignment and fused state at C5-6. On cervical myelo-CT scan (Fig. 6) and MR imaging, centrolateral osteophyte and foraminal narrowing at the left C5-6 level with cord signal change could be observed (Fig. 7). However, it seemed that this was not enough to explain the patient's symptoms. Thus, electromyography (EMG), nerve conduction velocity (NCV) and somatosensory evoked potential (SEP) were carried out, but no specific abnormal findings other than mild C5-6 radiculopathy on the left could be found. Also brain MR imaging taken 15 months prior was normal (Fig. 8). Patient's symptoms retrogressed and the pain and motor weakness worsened during admission. His initial VAS increased from 5 to 7 and his manual motor test scores decreased from 4- to 3 . While considering to perform another cervical surgery, we incidentally discovered a lung mass after a chest X-ray on pre-operative evaluation (Fig. 9A) and immediately took a chest CT scan which showed suspicious signs of lung cancer (Fig. 9B).

Suspected of brain metastasis, patient underwent brain MR imaging with gadolinium that showed $2.0 \times 2.5 \mathrm{~cm}$ sized a single mass in the lateral convexity of the right precentral gyrus with moderate peritumoral edema (Fig. 10). Surgical resection was carried out and the biopsy report concluded as a metastastic adenocarcinoma from lung. Thus, postoperative whole brain radiation therapy, chemotherapy and physical therapy were conducted. His paresthesia and neuropathic pain im-

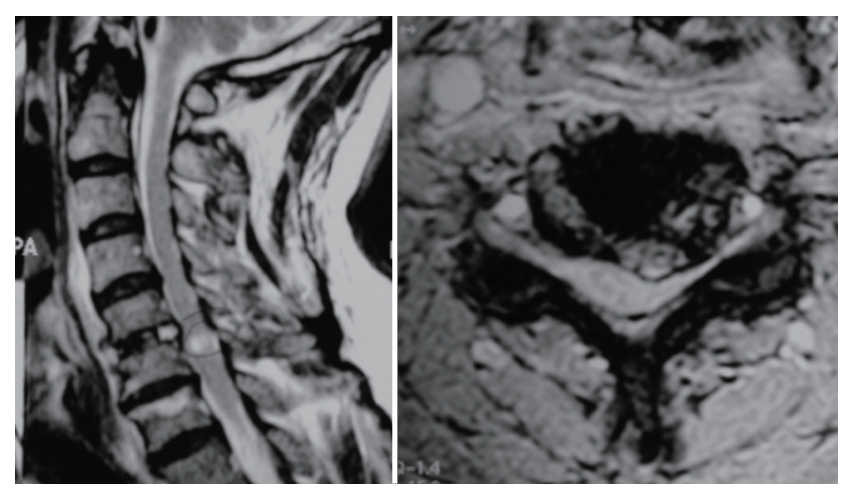

Fig. 7. Postoperative magnetic resonance images showing decompressed cervical C5-6 level but slight narrowing of the left foramen. 

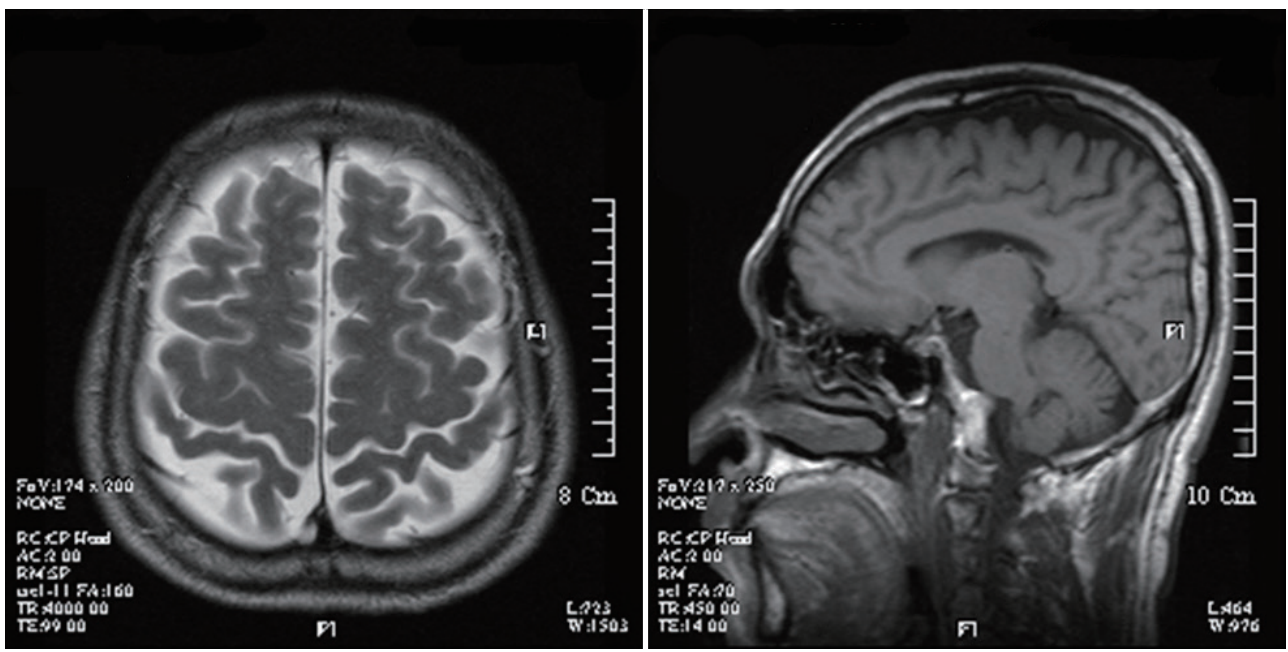

Fig. 8. Normal brain magnetic resonance imaging taken 15 months prior to admission to our hospital.
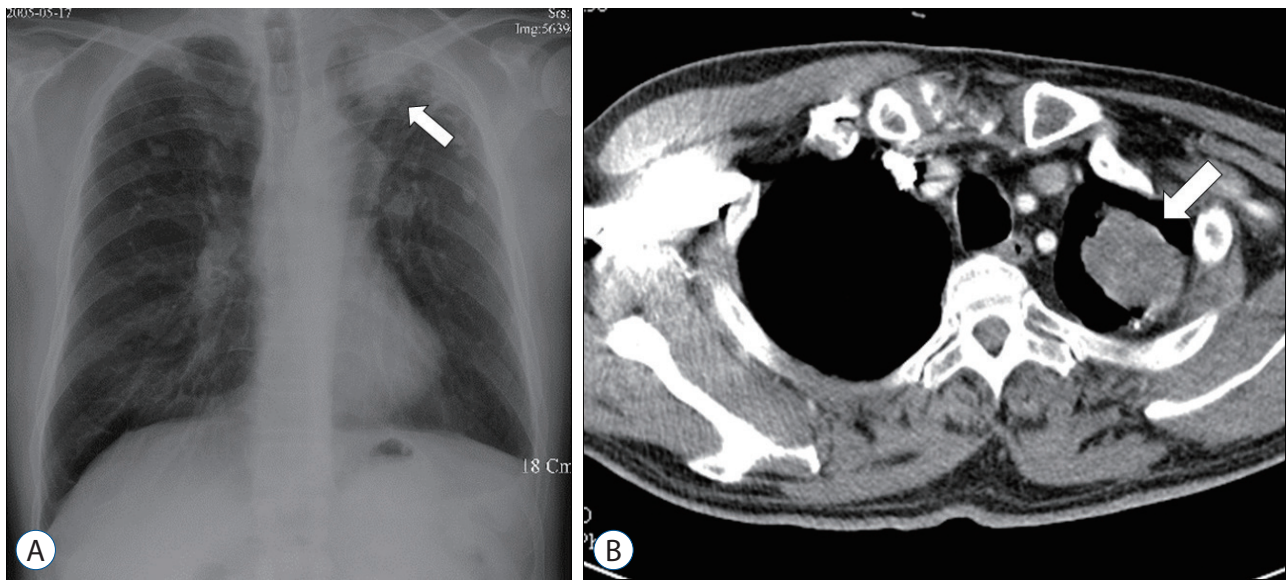

Fig. 9. A : A simple chest X-ray showing a large mass on the left upper lung (white arrow). B : A chest computerized tomography scan confirms a large mass on the left upper lung (white arrow).
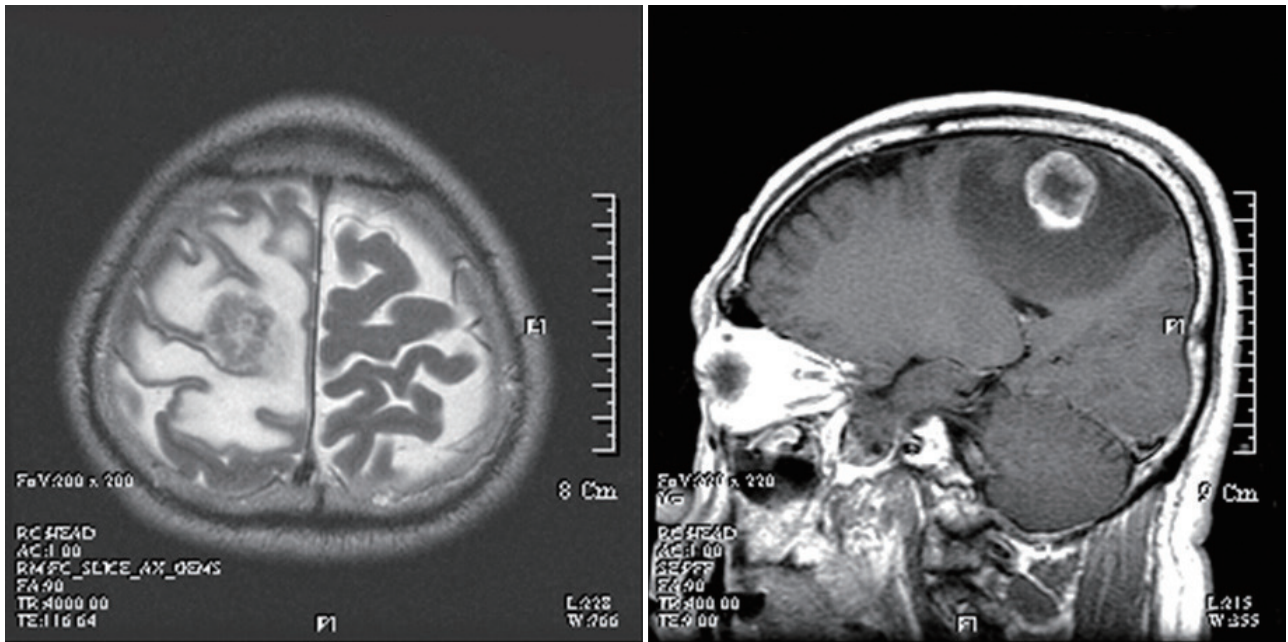

Fig. 10. New brain mass found on brain magnetic resonance imaging. 
Table 1. Summary of brain tumor cases presented with cervical radiculopathy

\begin{tabular}{|c|c|c|c|c|c|}
\hline Study & $\begin{array}{l}\text { Age } \\
\text { (years)/ } \\
\text { sex }\end{array}$ & Symptom and sign & Cervical lesion & Brain pathology/area & $\begin{array}{l}\text { Previous brain } \\
\text { evaluation }\end{array}$ \\
\hline $\begin{array}{l}\text { Clar and } \\
\text { Cianca }^{2)} \\
(1998)\end{array}$ & $55 / M$ & $\begin{array}{l}\text { Numbness in the second and third } \\
\text { distal phalanges of the left upper } \\
\text { limb }\end{array}$ & $\begin{array}{l}\text { C6-7 disc degeneration, C5-6 } \\
\text { left posterior disc herniation }\end{array}$ & $\begin{array}{l}\text { Glioblastoma multiforme/ } \\
\text { right precentral gyrus }\end{array}$ & No \\
\hline $\begin{array}{l}\text { Khalatbari et } \\
\text { al. }^{4)}(2008)\end{array}$ & $56 / F$ & $\begin{array}{l}\text { Radicular pain and paresthesia in the } \\
\text { right upper limb }\end{array}$ & $\begin{array}{l}\text { C5-6 disc degeneration and } \\
\text { right centrolateral osteophyte }\end{array}$ & $\begin{array}{l}\text { Meningioma/left parietal } \\
\text { somatosensory cortex }\end{array}$ & No \\
\hline $\begin{array}{l}\text { Huang et al. } \\
\text { (2018) }\end{array}$ & $54 / \mathrm{M}$ & $\begin{array}{l}\text { Numbness and weakness of the left } \\
\text { extremity }\end{array}$ & $\begin{array}{l}\text { C3-4, C4-5, C5-6 disc } \\
\text { herniation with compression } \\
\text { of the spinal cord }\end{array}$ & $\begin{array}{l}\text { Meningioma/right frontal } \\
\text { and frontal-parietal region } \\
\text { (two lobulated masses) }\end{array}$ & No \\
\hline \multirow[t]{2}{*}{$\begin{array}{l}\text { In present two } \\
\text { cases }\end{array}$} & $48 / \mathrm{M}$ & $\begin{array}{l}\text { Radicular pain and paresthesia in } \\
\text { both upper limbs and mild motor } \\
\text { weakness in the right upper limb }\end{array}$ & $\begin{array}{l}\text { C6-7 disc degeneration and } \\
\text { posterior osteophyte }\end{array}$ & $\begin{array}{l}\text { Meningioma/left frontal- } \\
\text { parietal area }\end{array}$ & $\begin{array}{l}\text { Brain MRI, } \\
2 \text { years prior }\end{array}$ \\
\hline & $56 / M$ & $\begin{array}{l}\text { Radicular pain and weakness in the } \\
\text { left upper limb }\end{array}$ & $\begin{array}{l}\text { C5-6 posterior osteophyte and } \\
\text { foraminal narrowing }\end{array}$ & $\begin{array}{l}\text { Metastastic lung cancer/ } \\
\text { right precentral gyrus }\end{array}$ & $\begin{array}{l}\text { Brain MRI, } 15 \\
\text { months prior }\end{array}$ \\
\hline
\end{tabular}

$M$ : male, $F$ : female, $M R I$ : magnetic resonance imaging

proved considerably and distal upper limb had improved but partial weakness remained (manual motor test, 4). He returned to the daily life and survived 2 and half years.

\section{DISCUSSION}

Cervical degenerative disease usually causes cervical radiculopathy including pain in the neck, shoulder, scapular and upper limb with or without paresthesia, hypesthesia and motor weakness corresponding to the involved cervical nerve root $^{1,6-8)}$. Image work ups such as X-rays, CT scans, magnetic resonance imaging (MRI) in the cervical area and EMG, NCV examinations, help physicians to make the correct diagnosis for patients. However, as in cases we display here in our study, it becomes very confusing if lesions concurrently exist at somatosensory or motor cortex lesions in the brain and in the cervical spine $e^{5)}$. Also, the two patients' myelopathic symptoms had dramatically improved after the brain surgery. Even though the authors aren't entirely sure if the pain related symptoms were relieved due to brain tumor removal or if it was due to pain medication, we believe its highly likely that the mass removal has helped greatly in the relief of pain.

To our knowledge, there were only three cases (Table 1) reported prior to this study, where treatment plan confusion occurred due to a brain tumor causing only cervical radiculopathy in patients who had cervical degenerative disease as well.
Khalatbari et al. ${ }^{4)}$ reported that a 56 year old woman suffered from radicular pain and paresthesia on her anterior upper arm and extending to her radial forearm and right thumb and index finger. Cervical MR imaging revealed a C5-6 disc degeneration with a right centrolateral bony spur causing compressive effects on the dural sac and right C6 nerve root. This was enough to be a compatible indication for cervical operation clinically and radiologically. Prior to the surgery, a MR imaging of the brain was taken because she complained of chronic intermittent headaches. Meningioma on the parietal somatosensory cortex was diagnosed however, the authors decided to perform cervical surgery because meningioma was not a definite surgical indication, in other words, a small lesion with no edema and mass effect. She underwent a C5-6 anterior discectomy and fusion with iliac crest but still complained of right hand pain and paresthesia. Finally, after resection of the meningioma was performed, her right hand pain, paresthesia and chronic headaches were resolved.

Huang and colleagues ${ }^{3}$ reported a case of brain meningioma that showed initial clinical symptoms similar to cervical radiculopathy including motor weakness in the left upper limb. MRI of the cervical spine showed herniation of the intervertebral disc in C3-4, C4-5, C5-6 with a compression of the ventral surface of the spinal cord. The numbness of the left upper limb was relieved for several days after conservative treatment, but the weakness persisted. Brain MR imaging with gadolium was carried out when the patient mentioned a 
skull deformity of the right parietal bone. It showed two lobulated and well defining brain tumors. After brain tumor excision, postoperative radiation therapy, and aggressive rehabilitation, the patient was able to perform better in daily activities.

Clar and Ciancas ${ }^{2)}$ reported the case of a middle-aged man with symptoms indicative of a cervical radiculopathy. The eventual rapid progression of symptoms led to the diagnosis of a glioblstoma multiforme and extensive surgical debulking was performed. After several months, he returned to work in a modified capacity.

What makes our study unique from previous reported cases is that brain MR imaging was performed prior to surgery. It was difficult for us to decide whether to do more brain MR imaging because both patients had shown normal brain images which were taken within 2 years. In the first case, the patient had a normal brain image 2 years prior as part of a health screening program but the symptoms and signs did not fully correlate with the results of cervical MR imaging. In the second case, the patient also had brain imaging done previously and if it were not for a radiologist's suspicious findings on a chest X-ray, the authors would have hesitated to evaluate the brain further.

\section{CONCLUSION}

We report two cases of simultaneous lesions in the brain and in the cervical spine that produced similar symptoms and confused treatment priorities. In these cases, the cause of cervical radiculopathy was first considered to be the result of a cervical degenerative disease but was later identified to be a brain tumor. Our team recommend that even if previous brain MR imaging was to be found normal, when the cervical symptoms and signs do not fully correlate with the image work up and EMG/NCV examinations, physicians should consider the possibility of a new brain lesion.

\section{CONFLICTS OF INTEREST}

No potential conflict of interest relevant to this article was reported.

\section{INFORMED CONSENT}

Informed consent was obtained from all individual participants included in this study.

\section{AUTHOR CONTRIBUTIONS}

\author{
Conceptualization : YJK, JSS \\ Data curation : JSS, YJK \\ Formal analysis : JSS, YJK \\ Methodology : YJK, SKL, CSC \\ Project administration : JSS, YJK \\ Visualization : YJK, SKL, CSC \\ Writing - original draft : JSS, YJK \\ Writing - review \& editing : YJK, SKL, CSC
}

\section{ORCID}

$\begin{array}{ll}\text { Jin-Shup So } & \text { https://orcid.org/0000-0001-5725-4536 } \\ \text { Young-Jin Kim } & \text { https://orcid.org/0000-0002-6770-3523 } \\ \text { Sang-Koo Lee } & \text { https://orcid.org/0000-0003-2500-9493 } \\ \text { Chun-Sung Cho } & \text { https://orcid.org/0000-0001-6077-652X }\end{array}$

\section{References}

1. Caridi JM, Pumberger $M$, Hughes AP : Cervical radiculopathy: a review. HSS J 7 : 265-272, 2011

2. Clar SA, Cianca JC : Intracranial tumor masquerading as cervical radiculopathy: a case study. Arch Phys Med Rehabil 79 : 1301-1302, 1998

3. Huang YH, Hong CZ, Wu WT, Li KT, Chou LW : Brain meningioma with initial manifestation similar to cervical radiculopathy: a case report. Neuropsychiatr Dis Treat 10 : 1175-1181, 2014

4. Khalatbari M, Ghalenoui H, Yahyavi ST, Borghei-Razavi H : Left somatosensory cortex tumor presented with radicular hand pain and paresthesia. Arch Iran Med 11 : 107-109, 2008

5. Lim TH, Choi SI, Yoo Jl, Choi YS, Lim YS, Sang BH, et al. : Thalamic pain misdiagnosed as cervical disc herniation. Korean J Pain 29 : 119-122, 2016

6. Makhni MC, Yeung CM, Riew KD : The art of diagnosis in the cervical spine. Neurospine $17: 695-703,2020$

7. Wainner RS, Gill H : Diagnosis and nonoperative management of cervical radiculopathy. J Orthop Sports Phys Ther 30 : 728-744, 2000

8. Wilson JRF, Badhiwala JH, Moghaddamjou A, Martin AR, Fehlings MG : Degenerative cervical myelopathy; a review of the latest advances and future directions in management. Neurospine 16 : 494-505, 2019 